\title{
OBJETO NULO E PRONOME PLENO NA RETOMADA ANAFÓRICA EM PB: UMA ANÁLISE EM CORPORA ESCRITOS COM CARACTERÍSTICAS DE FALA
}

\section{NULL OBJECT AND TONIC PRONOUN AND THEIR ANAPHORIC RELATION IN BP: AN ANALYSIS IN WRITTEN CORPORA WITH SPOKEN LANGUAGE TRAITS}

Gabriel de Ávila Othero Universidade Federal do Rio Grande do Sul Porto Alegre, Rio Grande do Sul, Brasil

Sonia Cyrino Universidade Estadual de Campinas Campinas, São Paulo, Brasil

Giulia Schabbach Universidade Federal do Rio Grande do Sul Porto Alegre, Rio Grande do Sul Brasil

Leonardo Madrid Universidade Federal do Rio Grande do Sul Porto Alegre, Rio Grande do Sul, Brasil

Rodrigo Rosito Universidade Federal do Rio Grande do Sul Porto Alegre, Rio Grande do Sul, Brasil

RESUMO: Neste trabalho, apresentaremos os resultados de nossa investigação sobre o fenômeno da retomada anafórica de objeto direto em PB analisando dois corpora escritos que apresentam características de oralidade e tentam se aproximar da fala: um corpus constituído de histórias em quadrinhos infantis e outro contendo postagens do Twitter. Investigamos esses corpora com dois objetivos: o primeiro é comparar duas hipóteses sobre a distribuição entre objetos nulos e pronomes (uma que leva em consideração os traços de animacidade e especificidade do antecedente do elemento anafórico e outra que considera o traço de gênero semântico do antecedente). Nosso segundo objetivo é determinar a distribuição entre objetos nulos, clíticos pronominais e pronomes plenos de $3^{\text {a }}$ pessoa na retomada anafórica de objetos diretos, para verificar se essa distribuição se aproxima mais ao que se reporta, na literatura, a estudos 
de língua falada ou escrita.

PALAVRAS-CHAVE: Objeto nulo; Retomada anafórica de objeto; Pronome; Gramática do Português Brasileiro.

ABSTRACT: In this article, we present the results of our research on the phenomenon of anaphoric direct object in PB by analyzing two corpora that present oral characteristics and try to mimic oral speech: a corpus consisting of children's comics and the other of Twitter posts. We investigate these corpora with two objectives in mind: the first is to compare two hypotheses about the distribution between null objects and pronouns (one that takes into account the features of animation and specificity of the antecedent of the anaphoric element and the other considers the semantic gender of the antecedent). Our second goal is to determine the distribution of null objects, pronominal clitics and 3rd person tonic pronouns in anaphoric direct objects, in order to verify if this distribution is closer to what is reported in literature in studies of spoken or written language.

KEYWORDS: Null object; Anaphoric relations; Pronoun; Brazilian Portuguese Grammar. 


\section{INTRODUÇÃO'}

$\mathrm{O}$ fenômeno do objeto nulo $(\mathrm{ON})$ em português brasileiro (PB) tem sido estudado com detalhe desde, pelo menos, os trabalhos clássicos de Galves (1989), Farrel (1990) e Cyrino (1993, 1994/1997). Esse fenômeno consta com registros em PB desde meados do século XIX, período que coincide com a queda dos pronomes clíticos de $3^{\mathrm{a}}$ pessoa e com a ocorrência de pronomes lexicais tônicos funcionando como objeto direto (CYRINO 1994/1997); ver exemplo (1) ${ }^{2}$. A retomada anafórica do objeto direto com uma categoria vazia (exemplo (2)) é uma "peculiaridade" gramatical do $\mathrm{PB}$, diferenciando nossa gramática, nesse aspecto, da gramática do português europeu e da de outras línguas românicas (RAPOSO, 1986; SCHWENTER, 2014; CYRINO \& MATOS, 2016).

(1) Fui no trabalho do mozão $o_{i}$, mas não vi ele $\mathrm{i}_{\mathrm{i}}$.

(2) Vi o "Esquadrão Suicida" ${ }_{i}$ e achei $\emptyset_{i}$ fraco.

Uma discussão sobre o fenômeno da retomada anafórica de objeto direto em PB que tem recebido novos olhares diz respeito a duas hipóteses distintas sobre os condicionadores internos que favoreceriam a retomada anafórica de objeto por categoria vazia (um $\mathrm{ON}$ ) ou por pronome pleno (ele/ela). Considerando que categoria vazia e pronome lexical não estejam exatamente em variação livre (ainda que tampouco estejam em distribuição complementar de maneira categórica, cf. referências já citadas), uma das questões envolvendo a retomada anafórica de objetos diretos é identificar os fatores condicionadores que favorecem o $\mathrm{ON}$ ou a retomada com um pronome pleno. Grande parte da literatura assume que a combinação dos traços de animacidade e especificidade do referente (CYRINO, 1993, 1994/1997; SCHWENTER \& SILVA, 2002, 2003; VIEIRA-PINTO \& COELHO, 2016, entre outros) são os fatores condicionadores básicos pela distribuição entre ONs e pronomes. É o que vemos nos exemplos (1) e (2) acima, repetidos abaixo por conveniência:

$$
\begin{array}{ll}
\text { Fui no trabalho do mozão }{ }_{i} \text {, mas não vi ele }{ }_{\mathrm{i}} . & (\text { referente }+\mathrm{a},+\mathrm{e}) \\
\text { Vi o "Esquadrão Suicida" }{ }_{i} \text { e achei } \varnothing_{\mathrm{i}} \text { fraco. } & \text { (referente }-\mathrm{a},+\mathrm{e})
\end{array}
$$

Nesse sentido, os antecedentes $[+\mathrm{a},+\mathrm{e}]$ e $[+\mathrm{a},-\mathrm{e}]$ favoreceriam a retomada por um pronome tônico, ao passo que antecedentes $[-\mathrm{a},+\mathrm{e}]$ e $[-\mathrm{a},-\mathrm{e}]$ favoreceriam a retomada anafórica por uma categoria vazia, o ON (cf. referências já citadas). Alternativamente, alguns trabalhos (PIVETTA, 2015; AYRES, 2016; OTHERO et al. 2016; COELHO et al. 2017) buscaram explorar uma hipótese lançada por Creus \& Menuzzi (2004), a hipótese do gênero semântico. De acordo com essa hipótese, um único traço semântico do antecedente, o traço de gênero semântico

\footnotetext{
${ }^{1}$ Agradecemos aos comentários de um dos pareceristas da Revista, por suas sugestões à edição final do texto.

${ }^{2}$ Todos os exemplos foram retirados de nossos corpora (ver seção 2).
} 
(ou "biológico") do referente, seria relevante no condicionamento da retomada anafórica de objeto direto em PB. De acordo com Othero \& Schwanke

O traço de gênero semântico diz respeito à classificação que distingue substantivos que denotam seres sexuados de substantivos que denotam seres não sexuados; ou, talvez de forma mais precisa, o traço distingue substantivos que denotam sexo natural aparente, como homem, mulher, professor, cachorro, etc., de substantivos que não denotam sexo natural aparente, como mesa, livro, vítima, cônjuge, boneco, tartaruga, etc. Referentes inanimados são marcados negativamente para esse traço; substantivos animados, contudo, não possuem necessariamente um gênero semântico específico: pessoa, habitante, estudante, etc. Ou seja, alguns substantivos possuem gênero gramatical, mas não gênero semântico inerente. A hipótese de Creus \& Menuzzi (2004) é, basicamente, de que o traço de gênero semântico do referente atua como gatilho essencial para a retomada anafórica de objetos em terceira pessoa (2008, p. 156-157).

Nas palavras de Creus \& Menuzzi

(...) destes dois traços [animacidade e especificidade], o que tem papel central é o de animacidade, já que é ele que configura as generalizações básicas do sistema (...). Assim, parece-nos que a explicação do sistema de anáfora de objeto em PB (...) precisa identificar no traço de animacidade aquele aspecto essencial que, ao mesmo tempo que traça as generalizações básicas, prevê também a possibilidade de alternativa para os antecedentes animados não-específicos. A nosso ver, o aspecto fundamental do traço de animacidade é que ele está associado com distinções de gênero semântico $(2004$, p. 7$)$.

Um único traço, portanto, seria suficiente para explicar como ocorre a distribuição de retomada anafórica de objeto direto em $\mathrm{PB}$, de maneira que, se o referente possui o traço $[+\mathrm{gs}]$, i.e. tem gênero semântico identificável, é preferencialmente retomado por um pronome; caso contrário, a retomada anafórica tenderia a ser feita com objeto nulo. É também o que mostramos nos exemplos (1) e (2) acima - repetidos uma vez mais, por conveniência.

Fui no trabalho do mozão, mas não vi ele ${ }_{i}$.

(referente $+\mathrm{gs}$ )

(2) Vi o "Esquadrão Suicida", e achei $\emptyset_{\mathrm{i}}$ fraco.

(referente-gs)

Neste artigo, apresentaremos os resultados de nossa investigação sobre o fenômeno da retomada anafórica de objeto direto em PB comparando justamente essas duas hipóteses (a da combinação de traços de especificidade e animacidade versus a de gênero semântico do referente anafórico) na distribuição entre objetos nulos e pronomes. Faremos isso com a análise de dois corpora escritos coletados 
por nós que - imaginamos - trazem características de oralidade e tentam se aproximar da fala. O primeiro corpus é constituído de histórias em quadrinhos infantis; o segundo, de postagens do Twitter ${ }^{3}$. Diversos trabalhos já mostraram que o ON é a principal estratégia de retomada anafórica de objeto em $\mathrm{PB}$ vernacular falado (MONTEIRO, 1994; BAGNO, 2011; OTHERO \& SPINELLI 2017, entre outros). Agora, pretendemos pesquisar gêneros envolvendo língua escrita que se aproxima da língua falada - ou, ao menos, que tenta, de alguma maneira, representá-la. Nos quadrinhos, os balões representam o diálogo falado pelos personagens - e serão essas falas que irão compor nosso primeiro corpus. Nas postagens do Twitter, a escrita é, via de regra, pouco monitorada e apresenta marcas da oralidade - como vimos nos exemplos (1) e (2), acima e como veremos em outros exemplos ao longo do texto.

Um segundo objetivo de nosso texto é verificar, em dois tipos de corpora escritos com marcas de oralidade, qual a distribuição entre objetos nulos, clíticos pronominais e pronomes plenos de $3^{\mathrm{a}}$ pessoa na retomada anafórica de objetos diretos. Sabemos que as estratégias desse tipo de retomada anafórica variam de acordo com o corpus analisado. Em corpora de fala vernacular do PB, a estratégia mais frequente é a retomada anafórica com ON (MONTEIRO, 1994; SCHWENTER \& SILVA, 2003; BAGNO, 2011; OTHERO \& SPINELLI, 2017). Em corpora escritos, entretanto, encontramos um número maior de clíticos e pronomes plenos, e menos casos de ONs do que encontramos em corpora de fala (OLIVEIRA, 2007; TESCH, YACOVENCO \& SCHERRE, 2014; OTHERO \& SCHWANKE, 2017). As investigações de Cyrino (1994/1997) e Marques de Sousa (2017), em peças teatrais, entretanto, mostrou que esse gênero de língua escrita privilegia o ON como estratégia de retomada anafórica de $3^{\mathrm{a}}$ pessoa em função de objeto direto em PB (ao contrário do que acontece em Português Europeu, por exemplo). Agora, além de investigarmos as duas hipóteses sobre o condicionamento do uso de pronomes plenos e ONs em PB (como mencionamos nos parágrafos anteriores), também verificaremos a distribuição dessas três estratégias (ON, pronome pleno e clítico) em corpora escritos com características de língua falada (histórias em quadrinhos infantis e postagens do Twitter).

O texto está organizado como segue: nesta primeira seção, apresentamos brevemente as duas hipóteses que tentam explicar a distribuição entre $\mathrm{ON}$ e pronome pleno na retomada do objeto anafórico em $\mathrm{PB}$ e nossos objetivos com o texto. Na seção 2, mostramos o resultado de nossa investigação no corpus coletado de histórias em quadrinhos; na seção 3, apresentamos e analisamos os dados que encontramos no corpus coletado do Twitter; na seção 4, discutimos os resultados dos dois corpora, destacando pontos em comum e pontos divergentes entre o que encontramos em cada corpus. Finalmente, nas considerações finais, resumimos e retomamos nossos resultados principais e indicamos os próximos caminhos de nossa investigação.

\footnotetext{
${ }^{3}$ Disponível em: $<$ http://www.twitter.com>.
} 


\section{ANÁLISE EM HISTÓRIAS EM QUADRINHOS}

Analisamos HQs infantis brasileiras da coleção de revistas Turma da Mônica. As revistas da Turma da Mônica são voltadas para o público infantil, e trabalhos de aquisição sintática do $\mathrm{PB}$ e sobre a linguagem infantil apontam para a generalização do $\mathrm{ON}$ (e da elipse de VP) como estratégia anafórica preferencial na linguagem infantil (OLIVEIRA, 2007; CASAGRANDE, 2007, 2012; AYRES, 2016, 2018). Na verdade, o ON é a principal estratégia de retomada anafórica do objeto em PB vernacular de $3^{\text {a }}$ pessoa também na fala adulta, como mencionamos na seção anterior. A retomada com um clítico não faz parte do vernáculo da língua, sendo o processo de escolarização responsável por "inserir" o clítico na gramática da criança (CORREA, 1991; OLIVEIRA, 2007). Por isso, esperávamos encontrar, na análise deste corpus, um número considerável de retomadas anafóricas de objeto justamente com objetos nulos ou com pronomes plenos, outra estratégia encontrada na fala vernacular em PB - e poucas ocorrências de retomadas anafóricas com pronomes clíticos, em contrapartida.

Para constituir este corpus de histórias em quadrinhos, analisamos 43 revistas, publicadas entre os anos 1990 e 2013, e encontramos 197 ocorrências de retomada anafórica de objeto direto, cujos referentes registramos e classificamos quanto aos traços de animacidade, especificidade e gênero semântico. Como mencionamos acima, nossa expectativa era encontrarmos preferência por objetos nulos e pronomes plenos e uma quantidade reduzida de clíticos, devido ao público-alvo infantil da revista e ao caráter oral das histórias em quadrinhos. Pensávamos que, por serem revistas infantis, as falas dos personagens trariam marcas da fala vernacular do $\mathrm{PB}$, acarretando, por exemplo, um vasto uso de ONs na retomada anafórica do objeto. Confirmando parcialmente nossas expectativas, encontramos (entre as 197 ocorrências de retomada que analisamos), 77 ocorrências de objetos nulos (39\%), 71 de pronomes plenos (36\%) e 49 de clíticos $(25)^{4}$.

\footnotetext{
${ }^{4} E ́$ interessante notar que Othero \& Schwanke (2017), em sua análise da retomada anafórica do objeto de $3^{\mathrm{a}}$ pessoa em corpus escrito, encontraram um percentual muito próximo de ocorrências de ON: 35\%. Entretanto, como eles investigaram língua escrita mais monitorada (textos de jornais populares contemporâneos), eles encontraram muito mais pronomes clíticos do que plenos: $62 \%$ de clíticos e apenas $2,5 \%$ de pronomes plenos. Isso evidencia que nossa expectativa com as histórias em quadrinhos estava parcialmente correta: encontramos mais $\mathrm{ONs}$ e pronomes plenos do que clíticos sendo usados na retomada anafórica do objeto de $3^{\mathrm{a}}$ pessoa. O número expressivo de clíticos, entretanto, não deixa de surpreender.
} 
Gráfico 1: distribuição entre as três estratégias de retomada de objeto no corpus de HQs.

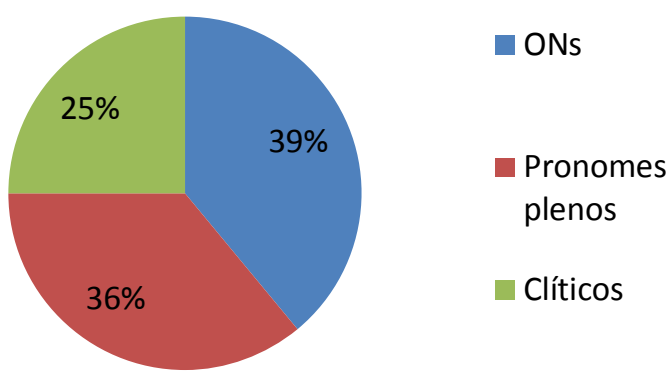

Fonte: Própria

Vejamos alguns exemplos:

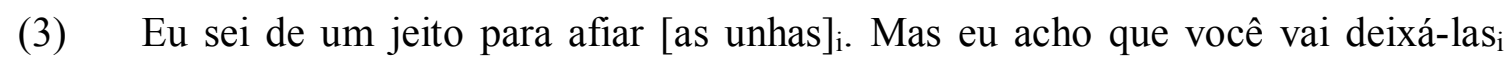
crescer!

(4) Tem [um peixinho novo no aquário]i, hein, Mingau? Só não vai inventar de pegar ele $_{i}$.

(5) (Cebolinha falando sobre os sapatos novos da Mônica) Vem, Cascão! Vamos batizar Ø.

Como discutimos na seção anterior, o uso do pronome pleno ou do objeto nulo não é aleatório e duas hipóteses parecem explicar essa distribuição em PB: a hipótese da combinação dos traços de animacidade e especificidade do referente e a hipótese do gênero semântico do referente (cf. referências citadas na seção anterior). Por isso, analisamos todas as ocorrências de pronomes plenos e ONs que encontramos, investigando justamente esses traços do referente. Nossos resultados foram os seguintes:

Tabela 2: retomadas com ONs e pronomes plenos e os traços do referente.

\begin{tabular}{|r|r|r|c|}
\hline & Objetos nulos & Pronomes plenos & Total \\
\hline$[+\mathrm{a},+\mathrm{e}]$ & $4(8,7 \%)$ & $\mathbf{4 2}(\mathbf{9 1 , 3 \% )}$ & $46(100 \%)$ \\
\hline$[+\mathrm{a},-\mathrm{e}]$ & $1(20 \%)$ & $\mathbf{4}(\mathbf{8 0} \%)$ & $5(100 \%)$ \\
\hline$[-\mathrm{a},+\mathrm{e}]$ & $\mathbf{5 7}(\mathbf{7 4 \% )}$ & $20(26 \%)$ & $77(100 \%)$ \\
\hline$[-\mathrm{a},-\mathrm{e}]$ & $\mathbf{1 5}(\mathbf{7 5 \%})$ & $5(25 \%)$ & $20(100 \%)$ \\
\hline
\end{tabular}

Fonte: Própria

Como já antecipado por Cyrino (1993, 1994/1997 e trabalhos subsequentes), os referentes animados e específicos, $[+\mathrm{a},+\mathrm{e}]$, favoreceram a retomada anafórica com pronomes plenos (ver exemplo 6).

(6) Mãe da Magali: Foi [o Mingau $]_{i}$ quem caiu, Magali! Por que você está chorando? Magali: É que ver ele ${ }_{i}$ machucadinho me deixa triste! 
Os referentes [+a, -e], por outro lado, são historicamente problemáticos. Eles não costumam apresentar uma tendência clara na retomada anafórica, e normalmente os estudos sobre ON e retomada pronominal do objeto apresentam poucas ocorrências desse tipo de antecedente ${ }^{5}$, à exceção de Schwenter \& Silva (2003) que encontraram 114 ocorrências de referentes [+a, -e] em sua análise do corpus do PEUL (Programa de Estudos sobre o Uso da Língua); dessas, 89,5\% foram retomadas por ONs - uma tendência que vai contra o que encontramos, apesar de termos encontrado apenas 5 ocorrências (4 delas sendo retomadas por pronomes plenos).

Os referentes não animados ([-a, +e] e [-a, -e], veja os exemplos a seguir) têm um comportamento muito semelhante, favorecendo a retomada anafórica com o objeto nulo, confirmando o que já havia sido encontrado em Cyrino (1993, 1994/1997) e Schwenter \& Silva (2003), por exemplo.

Mônica: Acho que [nossas panquecas $]_{\mathrm{i}}$ ficaram ótimas! $\quad[-\mathrm{a},+\mathrm{e}]$

Cascão: Deixa eu experimentar $\emptyset_{\mathrm{i}}$ !

(8) Nem sabem inventar [um espirro novo $]_{\mathrm{i}}$ ! Achei $\emptyset_{\mathrm{i}}$ ! "Atchonga” é legal! Duvido que alguém espirre assim! $\quad[-\mathrm{a},-\mathrm{e}]$

Comparativamente, também anotamos o traço de gênero semântico de cada referente, buscando verificar a hipótese inicialmente proposta por Creus \& Menuzzi (2004). Encontramos o seguinte:

Tabela 3: retomadas com ONs e pronomes plenos e o traço de gênero semântico do referente.

\begin{tabular}{|c|r|r|r|}
\hline & Objetos nulos & $\begin{array}{l}\text { Pronomes } \\
\text { plenos }\end{array}$ & \multicolumn{1}{l|}{ Total } \\
\hline$[+$ gs $]$ & $7(14,6 \%)$ & $\mathbf{4 1}(\mathbf{8 5}, \mathbf{4 \%})$ & $48(100 \%)$ \\
\hline$[$-gs $]$ & $\mathbf{7 0}(\mathbf{7 0 \%})$ & $30(30 \%)$ & $\begin{array}{r}\mathbf{1 0 0} \\
(\mathbf{1 0 0 \% )}\end{array}$ \\
\hline
\end{tabular}

Fonte: Própria

Como previsto por Creus \& Menuzzi (2004), os antecedentes com gênero semântico aparente favoreceram a retomada anafórica por pronomes plenos, ao passo que antecedentes sem gênero semântico favoreceram a retomada anafórica com objetos nulos (veja os exemplos 6 a 8 acima).

De acordo com Creus \& Menuzzi,

\footnotetext{
${ }^{5}$ Cyrino (1994/1997) encontrou apenas 7 ocorrências (4 sendo retomadas por ONs e 3 por pronomes); Oliveira (2007) encontrou apenas 4 ocorrências (1 sendo retomada por ON e 3 por pronomes); Pivetta (2015) traz 8 ocorrências (3 retomadas por ON e 5 por pronomes); Othero \& Schwanke (2017) encontraram 10 ocorrências (todas sendo retomadas por pronomes) e Othero \& Spinelli (2017) trazem apenas 8 ocorrências (todas retomadas por objetos nulos).
} 
Do ponto de vista conceitual, a hipótese que associa os pronomes plenos do $\mathrm{PB}$ à presença de gênero semântico, e objetos nulos à ausência de gênero semântico é mais natural que a hipótese análoga baseada na distinção de animacidade: afinal, a diferença básica entre as formas ele/ela e os objetos nulos é que as primeiras portam especificações de gênero, enquanto que os últimos são justamente não-especificados para gênero (bem como para número, mas nisso os ONs [objetos nulos] não diferem significativamente dos PrPls [pronomes plenos], já que os últimos podem ou não portar a flexão de número). Ou seja, a escolha entre ONs e PrPls resultaria, basicamente, de um processo de concordância entre antecedente e forma anafórica: antecedentes com gênero semântico favorecem o uso de PrPls porque estas são as formas anafóricas especificadas para gênero; e antecedentes sem gênero semântico favorecem o uso de ONs precisamente porque ONs não possuem especificação para gênero semântico (2004, p. 161).

Esses resultados, contudo, estão longe de ser categóricos. Ainda assim, obtemos certa polarização, como vimos, com ambas as hipóteses que investigamos aqui. Nas análises desse corpus, a hipótese da combinação dos traços de animacidade e especificidade tornou mais clara a leitura dos dados (cf. Tabela 1), apresentando resultados mais polarizados e confirmando a hipótese original defendida em Cyrino (1994/1997). Ou seja, os referentes animados, de maneira geral, favorecem a retomada pronominal, ao passo que os referentes não animados favorecem a retomada com o $\mathrm{ON}$ - o papel da especificidade não ficou claro em nossos resultados. Voltaremos a discutir esses resultados na seção final do artigo.

\section{ANÁLISE DAS POSTAGENS DO TWITTER}

Como dissemos na Introdução, também pesquisamos ocorrências de retomadas anafóricas de objeto de $3^{\mathrm{a}}$ pessoa em postagens do Twitter, uma rede social em que os usuários postam mensagens curtas num serviço de microblogging. Analisamos postagens de usuários brasileiros indiscriminada e aleatoriamente (mantivemos apenas o controle da data das postagens: 2016 e 2017, mas não controlamos faixa etária ou escolaridade dos autores dos posts). Via de regra, as postagens têm caráter de fala espontânea e refletem o vernáculo do PB - como veremos abaixo. Por isso, nossa expectativa era encontrar estratégias de retomada anafórica do objeto em distribuição próxima ao que encontramos reportado na literatura sobre o PB falado vernacular, i.e. predominância de ocorrências de objetos nulos, seguido por retomadas com pronomes plenos e a ausência (ou quase ausência) de pronomes clíticos de $3^{\mathrm{a}}$ pessoa. E foi justamente isso que encontramos: em 595 ocorrências de retomadas de objetos diretos anafóricos de $3^{\text {a }}$ pessoa que analisamos, encontramos a seguinte 
distribuição: 407 (68,4\%) ocorrências de ONs e 188 (31,6\%) de pronomes plenos (e nenhuma ocorrência de retomada por pronome clítico).

Gráfico 2: Distribuição entre as três estratégias de retomada de objeto no corpus de postagens do Twitter.

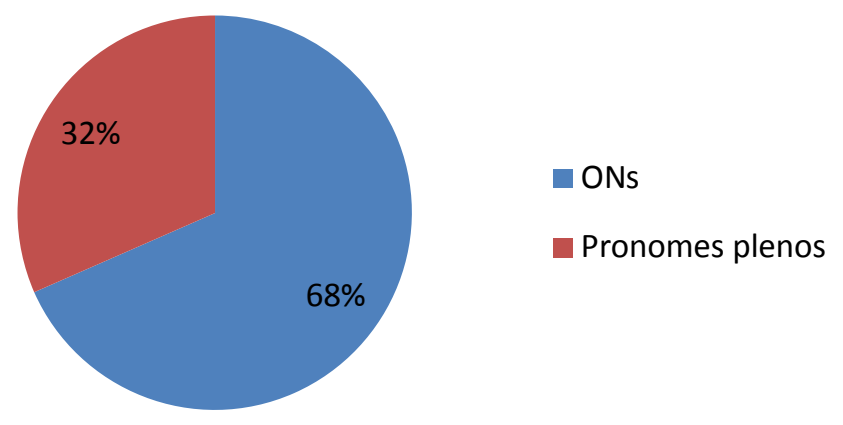

Fonte: Própria

Esses resultados estão, de fato, bem próximos aos que encontramos em língua falada. Monteiro (1994), por exemplo, em seu trabalho com os dados de fala do $\mathrm{NURC}^{6}$, reportou que $62,6 \%$ das retomadas anafóricas de objeto direto de $3^{\text {a }}$ pessoa foram de objeto nulo. Em um estudo mais recente, Othero \& Spinelli (2017), investigando dados de fala do corpus do $\mathrm{VARSUL}^{7}$, encontraram a seguinte distribuição: $78,1 \%$ de retomadas anafóricas de objeto com categoria vazia $(\mathrm{ON}), 18,3 \%$ com pronomes plenos e $3,6 \%$ com pronomes clíticos. Isso significa que os textos no Twitter, apesar de serem escritos pelos usuários, refletem características marcantes da fala, tal como a predominância das estratégias de retomada anafórica de objetos diretos de $3^{\text {a }}$ pessoa. (Outros estudos poderiam verificar a presença/ausência de outros traços característicos da fala vernacular do PB, tal como o uso de construções topicalizadas, a predominância da próclise, efeitos de concordância etc.). É interessante notar, inclusive, a total ausência da retomada por clíticos nos dados que pesquisamos do Twitter.

Comparando com o que encontramos no corpus de histórias em quadrinhos, chegamos ao seguinte quadro:

Tabela 4: Retomadas de objetos diretos nos dois corpora coletados.

\begin{tabular}{|c|c|r|}
\hline & Ocorrências (Twitter) & Ocorrências (HQs) \\
\hline Objeto nulo & $407(68,4 \%)$ & $77(39 \%)$ \\
\hline Pronome pleno & $188(31,6 \%)$ & $71(36 \%)$ \\
\hline Clítico & 0 & $49(25 \%)$ \\
\hline Total & $\mathbf{5 9 5}(\mathbf{1 0 0 \% )}$ & $\mathbf{1 9 7}(\mathbf{1 0 0 \% )}$ \\
\hline
\end{tabular}

Fonte: Própria

\footnotetext{
${ }^{6}$ NURC - Norma Urbana Culta; cf. Callou (1999), Castilho (2002).

${ }^{7}$ VARSUL - Variação Linguística na Região Sul do Brasil (www.varsul.org.br); cf.

Collischonn \& Monaretto (2012), Bisol \& Monaretto (2016).
} 
Repare como temos, no corpus do Twitter, representativamente mais ocorrências de ONs (68\% versus $39 \%$ no corpus das $\mathrm{HQs}$ ), ao passo que encontramos mais ou menos a mesma distribuição na retomada por pronomes plenos (em ambos os corpora, a retomada por pronomes plenos fica em torno de $1 / 3$ das ocorrências analisadas ${ }^{8}$ ). Isso é muito curioso, pois podemos perceber aí uma tendência (já sinalizada em estudos anteriores, ver DUARTE, 1989; CYRINO, 1993, 1996; MONTEIRO, 1994; NUNES, 1996, por exemplo) de desaparecimento dos clíticos pronominais de $3^{\mathrm{a}}$ pessoa: os textos que encontramos no corpus de histórias em quadrinhos representam discurso monitorado escrito (são textos revisados e publicados por uma editora com seu padrão de qualidade de publicações). Por isso, os diálogos ali presentes, ainda que tencionem representar a fala - e a fala infantil -, são publicados em meio escrito e trazem o peso da tradição literária escrita gramatical. Daí termos tantas ocorrências de clíticos pronominais de $3^{\mathrm{a}}$ pessoa $(1 / 4$ do total de ocorrências se deu com clíticos). Por outro lado, o Twitter parece representar a escrita não monitorada (ou pouco monitorada) que tenta, de fato, representar a fala. Uma amostra disso foi a completa ausência de pronomes clíticos de $3^{\mathrm{a}}$ pessoa.

De qualquer maneira, voltando à nossa análise das ocorrências do Twitter, dessas 595 ocorrências, encontramos a seguinte distribuição entre pronomes e ONs, com relação aos traços de seus antecedentes:

Tabela 5: Retomadas com ONs e pronomes plenos e os traços do referente.

\begin{tabular}{|c|c|c|c|}
\hline & $\begin{array}{c}\text { Objetos } \\
\text { nulos }\end{array}$ & $\begin{array}{c}\text { Pronomes } \\
\text { plenos }\end{array}$ & Total \\
\hline $\begin{array}{c}{[+\mathrm{a},} \\
+\mathrm{e}]\end{array}$ & $\mathrm{g}$ & $\mathbf{1 4 6}(\mathbf{8 0 , 6 \% )}$ & $\begin{array}{c}181 \\
(100 \%)\end{array}$ \\
\hline$[+\mathrm{a},-\mathrm{e}]$ & $5(45,5 \%)$ & $\mathbf{6}(\mathbf{5 4 , 5 \% )}$ & $11(100 \%)$ \\
\hline$[-\mathrm{a},+\mathrm{e}]$ & $\mathbf{3 3 8}(\mathbf{9 0 , 8} \%)$ & $34(9,1 \%)$ & $\begin{array}{c}372 \\
(100 \%)\end{array}$ \\
\hline$[-\mathrm{a},-\mathrm{e}]$ & $\mathbf{2 9}(\mathbf{9 3 , 5 \% )}$ & $2(6,4 \%)$ & $31(100 \%)$ \\
\hline
\end{tabular}

Fonte: Própria

Repare como encontramos aqui uma distribuição semelhante àquela do corpus das histórias em quadrinhos, independentemente de termos encontrado números totais um tanto distintos nas ocorrências. Ou seja, a distribuição que favorece o uso de plenos e nulos parece se manter estável nos dois corpora, o que indica que os traços do referente mantêm a tendência de distribuição entre as estratégias de retomada anafórica do objeto, independente do tipo de corpus investigado (essa mesma tendência pode ser atestada em corpus de fala ou outros tipos de escrita; ver trabalhos já citados):

\footnotetext{
${ }^{8}$ É interessante notar o grande número de pronomes plenos na função de objeto direto de $3^{\text {a }}$ pessoa no corpus de HQs (36\% das ocorrências). Isso parece demonstrar que os pronomes plenos de $3^{\mathrm{a}}$ pessoa estão deixando de ser estigmatizados nessa função, como argumentam, por exemplo, Othero \& Cardozo (2017).
} 
Gráfico 3: Pronomes plenos e seus antecedentes nos dois corpora analisados.

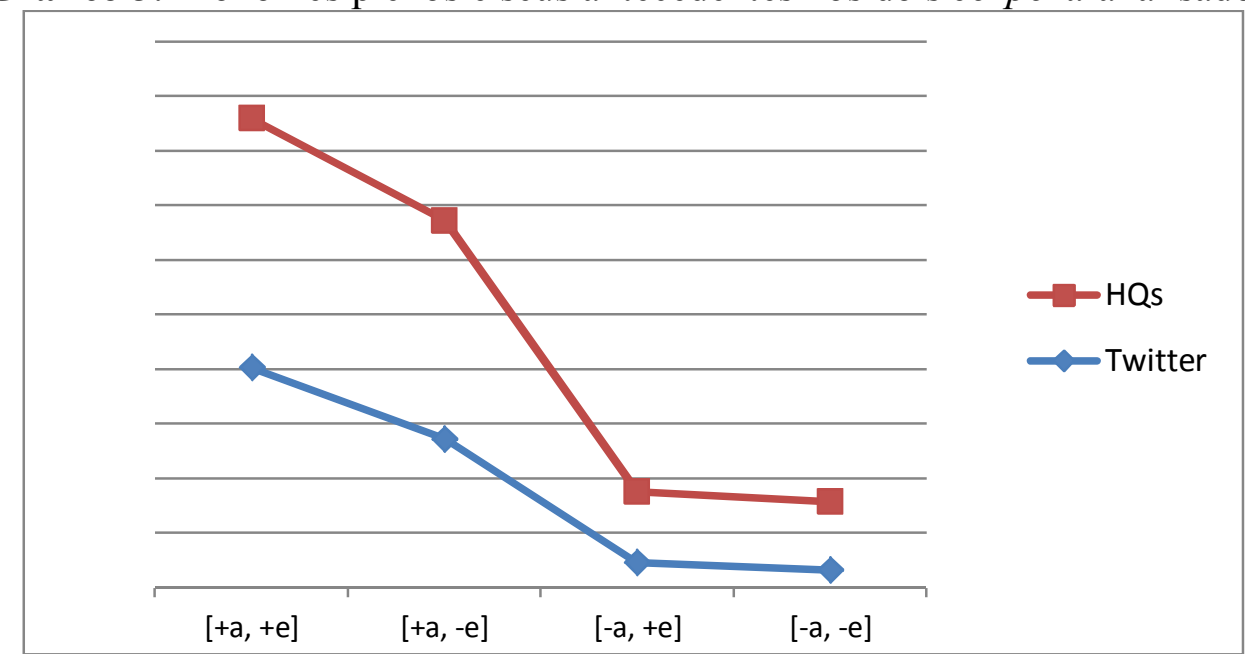

Fonte: Própria

Gráfico 4: ONs e seus antecedentes nos dois corpora analisados.

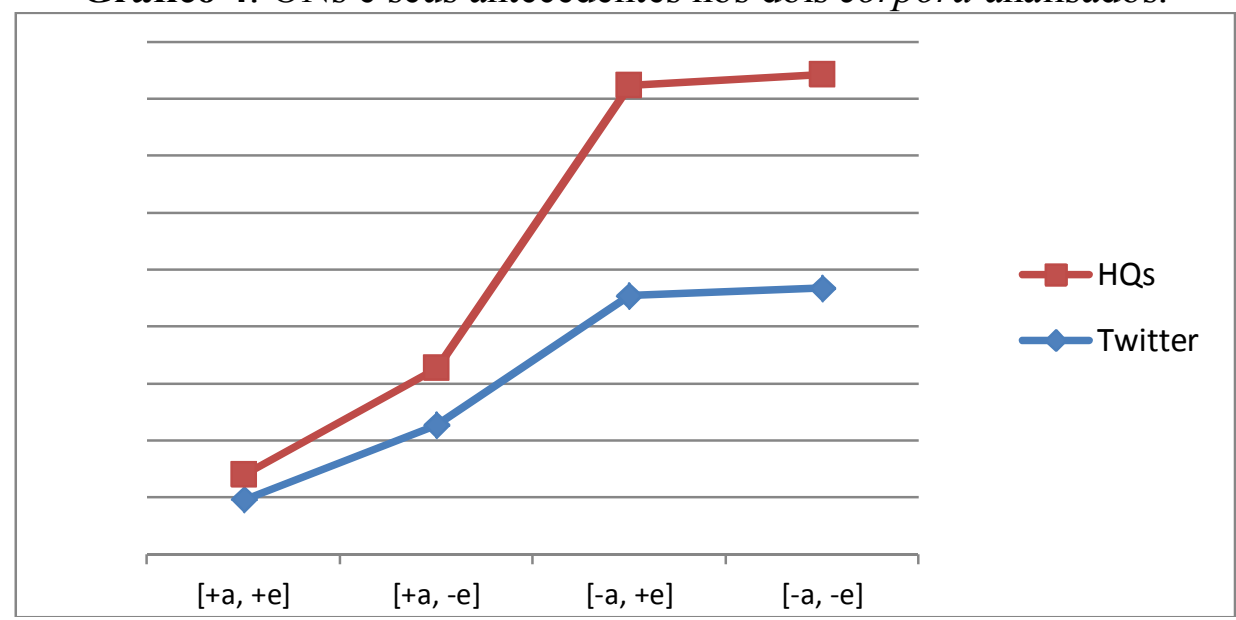

Fonte: Própria

Também aqui analisamos os antecedentes de cada pronome pleno e de cada ON com relação ao gênero semântico. Dessa vez, conseguimos visualizar uma polarização clara entre as duas estratégias de retomada anafórica, com referência ao traço de gênero semântico:

Tabela 6: Retomadas com ONs e pronomes plenos e o traço de gênero semântico do referente.

\begin{tabular}{|r|r|r|r|}
\hline & Objetos nulos & \multicolumn{1}{c|}{ Pronomes } & \multicolumn{1}{c|}{ Total } \\
\hline$[+$ gs $]$ & $29(15,5 \%)$ & $\mathbf{1 4 7}(\mathbf{8 4 , 5 \% )}$ & $176(100 \%)$ \\
\hline$[-g s]$ & $\mathbf{3 7 8}(\mathbf{9 0 , 2 \% )}$ & $41(9,8 \%)$ & $\mathbf{4 1 9 ( 1 0 0 \% )}$ \\
\hline
\end{tabular}

Fonte: Própria

Novamente, notamos que a tendência de um antecedente [+gs] ser retomado por um pronome e um antecedente [-gs] ser retomado por um ON se manteve muito próxima nos dois corpora analisados, como é possível verificar nos dois gráficos seguintes: 
Gráfico 5: pronomes plenos e seus antecedentes nos dois corpora analisados.

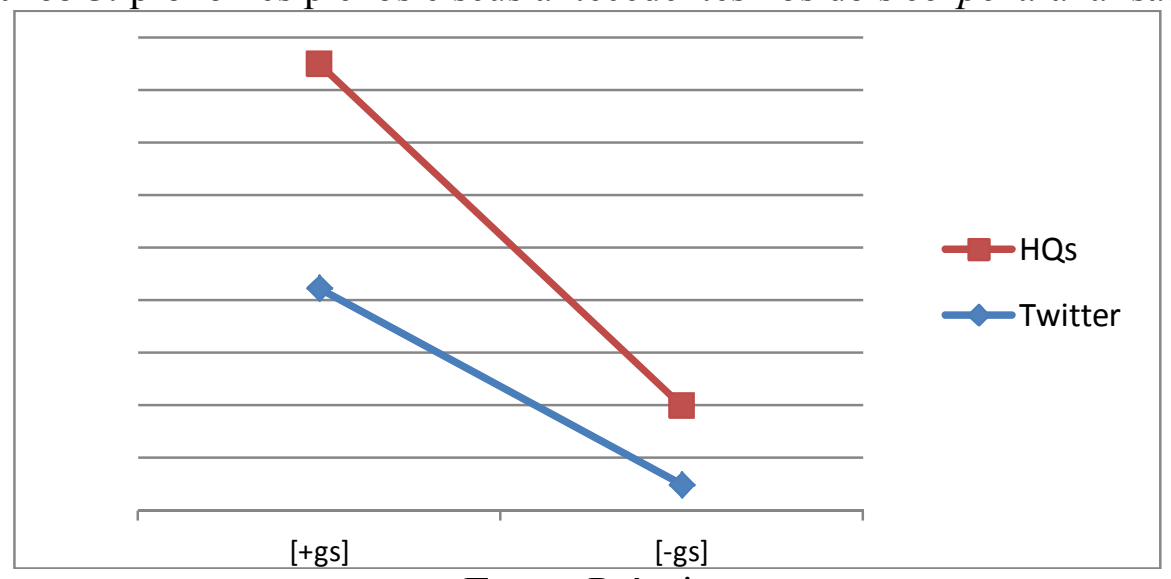

Fonte: Própria

Gráfico 6: ONs e seus antecedentes nos dois corpora analisados.

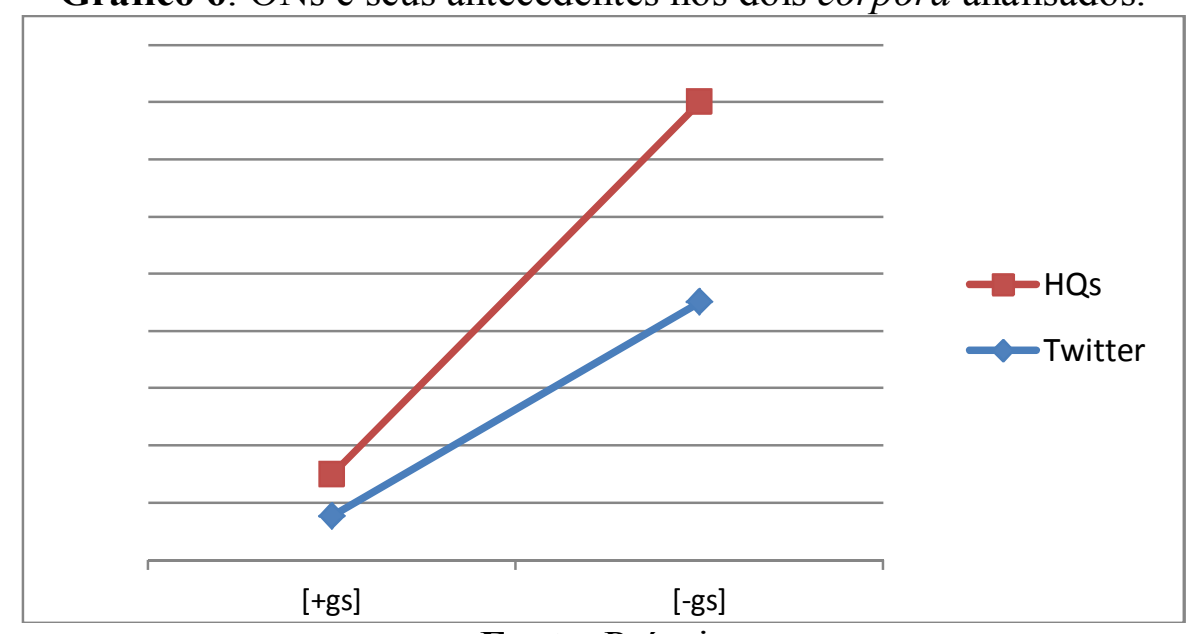

Fonte: Própria

\section{ANÁLISE DOS DOIS CORPORA}

Ambos são corpora de língua escrita. Entretanto, como vimos, ambos os corpora têm marcas de oralidade e, especialmente no caso das histórias em quadrinhos, ambos tentam, de fato, representar a fala. Contudo, no que toca à retomada anafórica de objeto direto de $3^{\mathrm{a}}$ pessoa em $\mathrm{PB}$, o corpus das histórias em quadrinhos se aproxima mais ao que costumamos encontrar em língua escrita padrão, i. e. encontramos presença significativa de clíticos pronominais de $3^{\mathrm{a}}$ pessoa (25\% das ocorrências, como vimos na seção 2) e frequência não predominante de ON (39\% das ocorrências) - números não esperados na investigação da fala vernacular em PB (referências já citadas). Um ponto que nos surpreendeu na análise desse corpus, contudo, foi o extenso número de retomadas anafóricas com pronomes plenos, ainda estigmatizados na escrita monitorada (TESCH, YACOVENCO \& SCHERRE, 2014). Como mencionamos anteriormente, isso parece indicar que a retomada com pronomes plenos pode estar deixando de ser estigmatizada e passando a servir como uma estratégia de retomada anafórica pronominal autorizada em $\mathrm{PB}$. 
Com o corpus do Twitter, por outro lado, encontramos um reflexo mais fidedigno da fala vernacular do $\mathrm{PB}$, pelo menos no que toca ao fenômeno estudado. Em 595 ocorrências de retomadas anafóricas de objeto direto de $3^{\mathrm{a}}$ pessoa, não encontramos um único clítico pronominal exercendo essa função. Em contrapartida, encontramos pronomes plenos (cerca de $1 / 3$ dos casos) e a predominância da estratégia do objeto nulo (cerca de $2 / 3$ dos casos), tal como encontramos na língua falada vernacular ${ }^{9}$ (referências já citadas). E podemos ver reflexos dessa diferença justamente no caso dos antecedentes que historicamente favorecem a retomada por $\mathrm{ON}$, os antecedentes com os traços [-a] e [-gs]. No corpus das histórias em quadrinhos, por termos um número reduzido de ONs, esse tipo de antecedente - ainda que tenha favorecido o $\mathrm{ON}$ - não apresentou um número expressivo, quando comparamos com o que encontramos no corpus do Twitter. É o que podemos ver na Tabela 7:

Tabela 7: Antecedentes [-a] e suas retomadas anafóricas em ambos os corpora.

\begin{tabular}{|c|c|r|r|}
\hline \multicolumn{4}{|c|}{ Histórias em quadrinhos } \\
\hline & $\begin{array}{l}\text { Objetos } \\
\text { nulos }\end{array}$ & $\begin{array}{l}\text { Pronomes } \\
\text { plenos }\end{array}$ & Total \\
\hline $\begin{array}{c}{[-\mathrm{a},} \\
+\mathrm{e}]\end{array}$ & $57(74 \%)$ & $20(26 \%)$ & $77(100 \%)$ \\
\hline$[-\mathrm{a},-\mathrm{e}]$ & $15(75 \%)$ & $5(25 \%)$ & $20(100 \%)$ \\
\hline \multicolumn{4}{|c|}{ Twitter } \\
\hline $\begin{array}{c}{[-\mathrm{a},} \\
+\mathrm{e}]\end{array}$ & $338(90,8 \%)$ & $34(9,1 \%)$ & $\begin{array}{r}372 \\
(100 \%)\end{array}$ \\
\hline$[-\mathrm{a},-\mathrm{e}]$ & $29(93,5 \%)$ & $2(6,4 \%)$ & $31(100 \%)$ \\
\hline
\end{tabular}

Fonte: Própria

Repare que, nos dados do corpus de HQs, há uma preferência pela retomada anafórica desse tipo de referente por objetos nulos ( $75 \%)$; contudo, a preferência é quase categórica nos dados do Twitter ( $93 \%)$. Verificando o traço de gênero semântico, chegamos a resultados muito próximos: uma tendência de antecedentes [-gs] serem retomados por ONs tanto no corpus de histórias em quadrinhos $(\sim 70 \%)$ como no corpus do Twitter $(\sim 90 \%)$, apresentando variação semelhante ao que percebemos antes. Ou seja, mais uma vez os dados que encontramos no corpus de mensagens do Twitter correspondem ao que encontramos reportado na literatura sobre a fala vernacular em PB: uma tendência muito grande de que antecedentes [-a] (ou [-gs]) sejam retomados por ONs.

\footnotetext{
${ }^{9}$ Lembramos o leitor que não investigamos as ocorrências de retomadas anafóricas com DPs.
} 


\section{CONSIDERAÇÕES FINAIS}

Ao final de nossa investigação, chegamos a algumas generalizações empíricas interessantes sobre as estratégias de retomada anafórica do objeto direto de $3^{\mathrm{a}}$ pessoa, considerando a natureza dos corpora que pesquisamos. Podemos resumi-las como segue:

3) O objeto nulo é uma estratégia frequente de retomada anafórica em corpus escrito com características de fala - o que corrobora os resultados de trabalhos anteriores, como Cyrino (1993, 1994/1997), por exemplo.

4) O pronome pleno também se mostrou como uma estratégia frequente no corpus que investigamos - algo que, salvo melhor juízo, nunca havia sido registrado em outros estudos sobre investigações do fenômeno em corpora escritos.

5) O clítico pronominal está, de fato, em desuso no vernáculo brasileiro não apenas em PB falado, como já mostraram diversos trabalhos (cf. referências mencionadas ao longo do texto), mas também no português escrito pouco monitorado (como foi o caso do corpus composto por mensagens do Twitter, como vimos). Os clíticos apareceram de maneira significativa, contudo, no nosso corpus de histórias em quadrinhos, comprovando (mais uma vez, cf. Oliveira 2007, por exemplo) que o uso de clíticos resulta diretamente da influência da escrita padrão e da escolarização.

6) Ambas as hipóteses que investigamos sobre o condicionamento gramatical da retomada anafórica de objeto pronominal ou nulo apresentam uma boa cobertura empírica dos fatos. Os testes estatísticos que rodamos (usamos o teste chi-quadrado de Pearson, que não mostraremos aqui por falta de espaço e por não ter se mostrado decisivamente relevante) apontaram tanto a animacidade (mas não a especificidade) quanto o gênero semântico como fatores relevantes para a retomada por pronome pleno ou objeto nulo. Esse resultado indica a proximidade entre os dois fatores, o que exigiria um estudo sintáticosemântico mais aprofundado da relação entre gênero e animacidade, já detectada como diversificada nas línguas naturais (CORBETT, 1991; DÄHL, 2000; ENGER, 2009, entre outros), a fim de explicar sua manifestação tão clara na sintaxe do $\mathrm{ON} /$ pronome pleno do PB.

7) A animacidade se provou fator essencial na retomada anafórica pronominal nos corpora analisados, o que corrobora, empiricamente, conclusões semelhantes encontradas tanto por trabalhos com outros tipos de corpora (cf. referências já mencionadas), como por trabalhos 
experimentais de correferência pronominal em PB (LEITÃO, 2005, 2010, por exemplo).

Apesar de ambas as hipóteses conseguirem explicar o fenômeno de maneira geral, ainda há casos inesperados, i.e. antecedentes [-a, -e]/[-gs] retomados por pronomes, ou antecedentes $[+\mathrm{a},+\mathrm{e}] \backslash[+\mathrm{gs}]$ retomados por ONs. Esses casos devem ser explicados em investigações futuras; não esboçamos uma explicação neste texto, mas certamente buscaremos tais explicações no andamento de nossos futuros trabalhos.

\section{REFERÊNCIAS}

AYRES, Mônica Rigo. Aspectos condicionadores do objeto nulo e do pronome pleno em português brasileiro: uma análise da fala infantil. Dissertação de Mestrado. PUCRS, Porto Alegre, 63f, 2016.

. "Objetos nulos, elipses de VP e retomadas pronominais na fala infantil em PB: uma reanálise do trabalho de Ayres e Othero" (2016). In: Domínios de Lingu@gem,v. 12, n. 1, 2018, p. 298-319.

BAGNO, Marcos. Gramática pedagógica do português brasileiro. São Paulo: Parábola, 2011.

BISOL, Leda; MONARETTO, Valéria. "Prefácio: VARSUL e suas origens, uma história sumariada". In: ReVEL, ed. especial n. 13, 2016, p. 6-11.

CALLOU, Dinah. "O projeto NURC no Brasil: da década de 70 à década de 90". In: Linguística, v. 11, 1999.

CASAGRANDE, Sabrina. A aquisição do objeto direto anafórico em português brasileiro. Dissertação de mestrado, UFSC, Florianópolis, 213f, 2007.

"Restrições de ocorrência do objeto direto anafórico no Português Brasileiro: gramática adulta e aquisição da linguagem". In: ReVEL, edição especial n. 6, 2012, p. 131-163.

CASTILHO, Ataliba Teixeira. "Apresentação - projeto de gramática do português falado". In: CASTILHO, Ataliba Teixeira. (org.) Gramática do português falado, vol. I: a ordem. $4^{\mathrm{a}}$ ed. Campinas: Ed. da Unicamp, 2002.

COELHO, Izete Lehmkuhl.; OTHERO, Gabriel de Ávila; VIEIRA-PINTO, Cecília Augusta. "Reanálise de variáveis semânticas no condicionamento do objeto nulo e do pronome pleno na fala de Florianópolis". In: Fórum Linguístico, v. 14, n. $4,2017$. 
COLLISCHONN, Gisela; MONARETTO, Valéria Neto. "Banco de dados VARSUL: a relevância de suas características e a abrangência de seus resultados". In: ALFA: Revista de Linguística, v. 56, n. 3, 2012.

CORBETT, Greville. Gender. Cambridge University Press, Cambridge, 1991.

CORREA, Vilma Reche. O objeto direto nulo no português do Brasil. Dissertação de Mestrado. Unicamp, Campinas, 97f, 1991.

CREUS, Suzana; MENUZZI, Sérgio de Moura. "Sobre o papel do gênero semântico na alternância entre objetos nulos e pronomes plenos em português brasileiro". In: Revista da ABRALIN, v. 3, n. 1-2, 2004, p. 149-176.

CYRINO, Sonia. "Observações sobre a mudança diacrônica no português do Brasil: objeto nulo e clíticos". In: Português brasileiro: uma viagem diacrônica. Campinas: Editora da Unicamp, 1993, p. 163-185.

CYRINO, Sonia. O objeto nulo no português do Brasil: um estudo sintáticodiacrônico. Tese de doutorado, Unicamp, Campinas, 1994. (Publicada em 1997 pela Editora da Universidade Estadual de Londrina)

AYRES, Mônica Rigo. Aspectos condicionadores do objeto nulo e do pronome pleno em português brasileiro: uma análise da fala infantil. Dissertação de Mestrado. PUCRS, Porto Alegre, 63f, 2016.

. "Objetos nulos, elipses de VP e retomadas pronominais na fala infantil em PB: uma reanálise do trabalho de Ayres e Othero" (2016). In: Domínios de Lingu@gem, v. 12, n. 1, 2018, p. 298-319.

BAGNO, Marcos. Gramática pedagógica do português brasileiro. São Paulo: Parábola, 2011.

BISOL, Leda; MONARETTO, Valéria. "Prefácio: VARSUL e suas origens, uma história sumariada". In: ReVEL, ed. especial n. 13, 2016, p. 6-11.

CALLOU, Dinah. "O projeto NURC no Brasil: da década de 70 à década de 90". In: Linguística, v. 11, 1999.

CASAGRANDE, Sabrina. A aquisição do objeto direto anafórico em português brasileiro. Dissertação de mestrado, UFSC, Florianópolis, 213f, 2007.

- "Restrições de ocorrência do objeto direto anafórico no Português Brasileiro: gramática adulta e aquisição da linguagem". In: ReVEL, edição especial n. 6, 2012, p. 131-163.

CASTILHO, Ataliba Teixeira. "Apresentação - projeto de gramática do português falado". In: CASTILHO, Ataliba Teixeira. (org.) Gramática do português falado, vol. I: a ordem. $4^{\mathrm{a}}$ ed. Campinas: Ed. da Unicamp, 2002. 
COELHO, Izete Lehmkuhl.; OTHERO, Gabriel de Ávila; VIEIRA-PINTO, Cecília Augusta. "Reanálise de variáveis semânticas no condicionamento do objeto nulo e do pronome pleno na fala de Florianópolis". In: Fórum Linguístico, v. 14, n. $4,2017$.

COLLISCHONN, Gisela; MONARETTO, Valéria Neto. "Banco de dados VARSUL: a relevância de suas características e a abrangência de seus resultados". In: ALFA: Revista de Linguística, v. 56, n. 3, 2012.

CORBETT, Greville. Gender. Cambridge University Press, Cambridge, 1991.

CORREA, Vilma Reche. O objeto direto nulo no português do Brasil. Dissertação de Mestrado. Unicamp, Campinas, 97f, 1991.

CREUS, Suzana; MENUZZI, Sérgio de Moura. "Sobre o papel do gênero semântico na alternância entre objetos nulos e pronomes plenos em português brasileiro". In: Revista da ABRALIN, v. 3, n. 1-2, 2004, p. 149-176.

CYRINO, Sonia. "Observações sobre a mudança diacrônica no português do Brasil: objeto nulo e clíticos". In: Português brasileiro: uma viagem diacrônica. Campinas: Editora da Unicamp, 1993, p. 163-185.

CYRINO, Sonia. O objeto nulo no português do Brasil: um estudo sintáticodiacrônico. Tese de doutorado, Unicamp, Campinas, 1994. (Publicada em 1997 pela Editora da Universidade Estadual de Londrina)

CYRINO, Sonia; MATOS, Gabriela. "Null objects and VP ellipsis in European and Brazilian Portuguese". In: WETZELS, Leo; COSTA, João; MENUZZI, Sergio de Moura. The handbook of Portuguese linguistics. Oxford: Blackwell, 2016.

DAHL, Östen. "Animacy and the notion of semantic gender". In: UNTERBECK, Barbara, et al. (orgs.), Gender in Grammar and Cognition. Mouton de Gruyter, Berlin, 2000.

DUARTE, Maria Eugenia. "Clítico acusativo, pronome lexical e categoria vazia no português do Brasil". In: TARALLO, Fernando. (org.) Fotografias sociolinguísticas. Campinas: Pontes, 1989.

ENGER, Hans-Olav. "The role of core and non-core semantic rules in gender assignment". In: Lingua 119, 2009, p. 1281-1299.

FARRELL, Patrick. "Null objects in Brazilian Portuguese". In: Natural Language \& Linguistic Theory, v. 8, n. 3, 1990, p. 325-346.

GALVES, Charlotte. "O objeto nulo em português brasileiro: percurso de uma pesquisa". In: Cadernos de Estudos Linguísticos 17, 1989, p. 65-90. 
LEITAO, Márcio. Processamento do objeto direto anafórico em Português Brasileiro. Tese de Doutorado. Faculdade de Letras, Universidade Federal do Rio de Janeiro, 149 f., 2005.

. "Animacidade e paralelismo estrutural no processamento da correferência". In: Linguística (Rio de Janeiro), v. 6, 2010, p. 44-57.

MARQUES DE SOUSA, Aantonio. As realizações do acusativo anafórico no Português Europeu e Brasileiro: um estudo diacrônico. Dissertação de Mestrado, 127f. UFRJ, Rio de Janeiro, 2017.

MONTEIRO, José Lemos. Pronomes pessoais: subsídios para uma gramática do português do Brasil. Fortaleza: Edições UFC, 1994.

NUNES, Jairo. "Direção de cliticização, objeto nulo e pronome tônico na posição de objeto em português brasileiro". In: ROBERTS, Ian; KATO, Mary (orgs.) Português brasileiro: uma viagem diacrônica. Campinas: Unicamp, 1996.

OLIVEIRA, Solange Mendes. "Objeto direto nulo, pronome tônico de $3^{\text {a }}$ pessoa, SN anafórico e clítico acusativo no português brasileiro: uma análise de textos escolares". In: ReVEL, v. 5, n. 9, 2007, p. 1-30.

OTHERO, Gabriel de Ávila; AYRES, Mônica Rigo; SCHWANKE, Camila; SPINELLI, Ana Carolina. "A relevância do traço gênero semântico na realização do objeto nulo em português brasileiro". In: Working Papers em Linguística v. 17(1), 2016, p. 64-86.

OTHERO, Gabriel de Ávila; SCHWANKE, Camila. "Retomadas anafóricas de objeto direto em português brasileiro escrito". In: Revista de Estudos da Linguagem, v. 26, n. 1, 2018, p. 147-185.

OTHERO, Gabriel de Ávila; CARDOZO, Rubia Wildner. "A ordem pronominal em português brasileiro: da ênclise à próclise, do clítico ao tônico" (or There and Back Again, a Word Order's Holiday). In: Fórum Linguístico, n. 14, 2017, p. 1717-1734.

OTHERO, Gabriel de Ávila; SPINELLI, Ana Carolina. "Analisando a retomada anafórica do objeto direto em português falado". In: Revista Letras (UFPR), v. 96, 2017, p. 174-195.

PIVETTA, Vera. Objeto direto anafórico no português brasileiro: uma discussão sobre a importância dos traços semântico-pragmáticos animacidade/especificidade vs. gênero semântico. Dissertação de mestrado. UFRGS, Porto Alegre, 131f, 2015.

RAPOSO, Eduardo Paiva. "On the null object in European Portuguese". In: JAEGGLI, Osvaldo; SILVA-CORVALÁN, Carmen. (eds.) Studies in Romance Linguistics. Foris: Dordrecht, 1986. 
SCHWENTER, Scott. "Two kinds of differential object marking in Portuguese and Spanish". In: AMARAL, Patricia; CARVALHO, Ana Maria. (orgs.) Portuguese-Spanish Interfaces: Diachrony, synchrony, and contact. Philadelphia: John Benjamins Publishing, 2014, p. 237-260.

SCHWENTER, Scott; SILVA, Glaucia. "Overt vs. null direct objects in spoken Brazilian Portuguese: a semantic/pragmatic account". In: Hispania, v. 85 n. 3, 2002, p. 577-586.

SCHWENTER, Scott; SILVA, Glaucia. "Anaphoric direct objects in spoken Brazilian Portuguese: semantics and pragmatics". In: Revista Internacional de Lingüística Iberoamericana, v. 1, n. 2, 2003, p. 99-123.

TESCH, Leila Maria; YACOVENCO, Lilia Coutinho; SCHERRE, Martha. "Variação e mudança na fala e na escrita: caminhos e fronteiras". In: Revista (Con)Textos Linguísticos, Vitória, v. 8, n. 10.1, 2014, p. 87-106.

VIEIRA-PINTO, Cecília Augusta; COELHO, Izete Lehmkuhl. "O objeto direto anafórico de SN: uma análise da fala de Florianópolis em duas sincronias". In: ReVEL, edição especial n. 13, 2016, p. 245-263.

CYRINO, Sonia; MATOS, Gabriela. "Null objects and VP ellipsis in European and Brazilian Portuguese". In: WETZELS, Leo; COSTA, João; MENUZZI, Sergio de Moura. The handbook of Portuguese linguistics. Oxford: Blackwell, 2016.

DAHL, Östen. "Animacy and the notion of semantic gender". In: UNTERBECK, Barbara, et al. (orgs.), Gender in Grammar and Cognition. Mouton de Gruyter, Berlin, 2000.

DUARTE, Maria Eugenia. "Clítico acusativo, pronome lexical e categoria vazia no português do Brasil". In: TARALLO, Fernando. (org.) Fotografias sociolinguísticas. Campinas: Pontes, 1989.

ENGER, Hans-Olav. "The role of core and non-core semantic rules in gender assignment”. In: Lingua 119, 2009, p. 1281-1299.

FARRELL, Patrick. "Null objects in Brazilian Portuguese". In: Natural Language \& Linguistic Theory, v. 8, n. 3, 1990, p. 325-346.

GALVES, Charlotte. "O objeto nulo em português brasileiro: percurso de uma pesquisa". In: Cadernos de Estudos Linguísticos 17, 1989, p. 65-90.

LEITAO, Márcio. Processamento do objeto direto anafórico em Português Brasileiro. Tese de Doutorado. Faculdade de Letras, Universidade Federal do Rio de Janeiro, 149 f., 2005.

"Animacidade e paralelismo estrutural no processamento da correferência". In: Linguística (Rio de Janeiro), v. 6, 2010, p. 44-57. 
MARQUES DE SOUSA, Aantonio. As realizações do acusativo anafórico no Português Europeu e Brasileiro: um estudo diacrônico. Dissertação de Mestrado, 127f. UFRJ, Rio de Janeiro, 2017.

MONTEIRO, José Lemos. Pronomes pessoais: subsídios para uma gramática do português do Brasil. Fortaleza: Edições UFC, 1994.

NUNES, Jairo. "Direção de cliticização, objeto nulo e pronome tônico na posição de objeto em português brasileiro". In: ROBERTS, Ian; KATO, Mary (orgs.) Português brasileiro: uma viagem diacrônica. Campinas: Unicamp, 1996.

OLIVEIRA, Solange Mendes. "Objeto direto nulo, pronome tônico de $3^{\mathrm{a}}$ pessoa, SN anafórico e clítico acusativo no português brasileiro: uma análise de textos escolares". In: ReVEL, v. 5, n. 9, 2007, p. 1-30.

OTHERO, Gabriel de Ávila; AYRES, Mônica Rigo; SCHWANKE, Camila; SPINELLI, Ana Carolina. "A relevância do traço gênero semântico na realização do objeto nulo em português brasileiro". In: Working Papers em Linguística v. 17(1), 2016, p. 64-86.

OTHERO, Gabriel de Ávila; SCHWANKE, Camila. "Retomadas anafóricas de objeto direto em português brasileiro escrito". In: Revista de Estudos da Linguagem, v. 26, n. 1, 2018, p. 147-185.

OTHERO, Gabriel de Ávila; CARDOZO, Rubia Wildner. "A ordem pronominal em português brasileiro: da ênclise à próclise, do clítico ao tônico" (or There and Back Again, a Word Order's Holiday). In: Fórum Linguístico, n. 14, 2017, p. 1717-1734.

OTHERO, Gabriel de Ávila; SPINELLI, Ana Carolina. "Analisando a retomada anafórica do objeto direto em português falado". In: Revista Letras (UFPR), v. 96, 2017, p. 174-195.

PIVETTA, Vera. Objeto direto anafórico no português brasileiro: uma discussão sobre a importância dos traços semântico-pragmáticos animacidadelespecificidade vs. gênero semântico. Dissertação de mestrado. UFRGS, Porto Alegre, 131f, 2015.

RAPOSO, Eduardo Paiva. "On the null object in European Portuguese". In: JAEGGLI, Osvaldo; SILVA-CORVALÁN, Carmen. (eds.) Studies in Romance Linguistics. Foris: Dordrecht, 1986.

SCHWENTER, Scott. "Two kinds of differential object marking in Portuguese and Spanish". In: AMARAL, Patricia; CARVALHO, Ana Maria. (orgs.) Portuguese-Spanish Interfaces: Diachrony, synchrony, and contact. Philadelphia: John Benjamins Publishing, 2014, p. 237-260. 
SCHWENTER, Scott; SILVA, Glaucia. "Overt vs. null direct objects in spoken Brazilian Portuguese: a semantic/pragmatic account". In: Hispania, v. 85 n. 3, 2002, p. 577-586.

SCHWENTER, Scott; SILVA, Glaucia. "Anaphoric direct objects in spoken Brazilian Portuguese: semantics and pragmatics". In: Revista Internacional de Lingüistica Iberoamericana, v. 1, n. 2, 2003, p. 99-123.

TESCH, Leila Maria; YACOVENCO, Lilia Coutinho; SCHERRE, Martha. "Variação e mudança na fala e na escrita: caminhos e fronteiras". In: Revista (Con)Textos Linguísticos, Vitória, v. 8, n. 10.1, 2014, p. 87-106.

VIEIRA-PINTO, Cecília Augusta; COELHO, Izete Lehmkuhl. "O objeto direto anafórico de SN: uma análise da fala de Florianópolis em duas sincronias". In: ReVEL, edição especial n. 13, 2016, p. 245-263.

Gabriel de Ávila Othero Gab.Othero@gmail.com

Sonia Cyrino

Sonia.Cyrino@gmail.com

Giulia Schabbach

GiuliaSchabbach@hotmail.com

Leonardo Madrid Leonardo.Madrid@ufrgs.br

Rodrigo Rosito

RodrigoRosito@gmail.com

Recebido em: 1 mar. 2018

Aceito em: 11 abr. 2018

Publicado em: 19 ago. 2018 